\title{
Pain and pain-related interference in adults with lower-limb amputation: Comparison of knee-disarticulation, transtibial, and transfemoral surgical sites
}

\author{
James Behr, MD; ${ }^{*}$ Janna Friedly, MD; ${ }^{1}$ Ivan Molton, PhD; ${ }^{1}$ David Morgenroth, MD; ${ }^{1}$ Mark P. Jensen, PhD; ${ }^{1}$ \\ Douglas G. Smith, $\mathbf{M D}^{\mathbf{2}}$ \\ Departments of ${ }^{1}$ Rehabilitation Medicine and ${ }^{2}$ Orthopedics, University of Washington School of Medicine, Seattle, WA
}

\begin{abstract}
Pain and pain-related interference with physical function have not been thoroughly studied in individuals who have undergone knee-disarticulation amputations. The principal aim of this study was to determine whether individuals with knee-disarticulation amputations have worse pain and painrelated interference with physical function than do individuals with transtibial or transfemoral amputations. We analyzed crosssectional survey data provided by 42 adults with lower-limb amputations. These individuals consisted of 14 adults reporting knee-disarticulation amputation in one limb and best-matched cases (14 reporting transfemoral amputation and 14 reporting transtibial amputation) from a larger cross-sectional sample of 472 individuals. Participants were rigorously matched based on time since amputation, reason for amputation, age, sex, diabetes diagnosis, and pain before amputation. Continuous outcome variables were analyzed by one-way analysis of variance. Categorical outcomes were analyzed by Pearson chi-square statistic. Given the relatively small sample size and power concerns, mean differences were also described by estimated effect size (Cohen's $d$ ). Of the 42 participants, 83\% were male. They ranged in age from 36 to 85 (median $=55.1$, standard deviation $=$ 11.0). Most amputations were of traumatic origin (74\%), and participants were on average 12.4 years from their amputations at the time of the survey. Individuals with transtibial amputation reported significantly more prosthesis use than did individuals with knee-disarticulation amputation. Amputation levels did not significantly differ in phantom limb pain, residual limb pain, back pain, and pain-related interference with physical function. Estimates of effect size, however, indicated that participants with knee-disarticulation amputation reported less phantom limb pain, phantom limb pain-related interference with physical function, residual limb pain, residual limb pain-related interference with physical function, and back pain-related interference with
\end{abstract}

physical function than did participants with transtibial or transfemoral amputations. This study demonstrated that patients with knee-disarticulation amputation used prostheses significantly less than did patients with transtibial amputation. However, no evidence was found that patients with knee-disarticulation amputation have worse outcomes in terms of pain and painrelated interference with physical function; in fact, they may have more favorable long-term outcomes.

Key words: back pain, knee disarticulation, knee-disarticulation amputation, LEAP, matched case design, pain, pain-related interference, phantom limb pain, prosthesis use, residual limb pain.

\section{INTRODUCTION}

More than an estimated 100,000 lower-limb amputations are performed each year in the United States [1],

\footnotetext{
Abbreviations: ANOVA $=$ analysis of variance, LEAP = Lower Extremity Assessment Project, SD = standard deviation, SIP = Sickness Impact Profile.

*Address all correspondence to James Behr, MD; Department of Rehabilitation Medicine, University of Washington School of Medicine, 1959 NE Pacific St, Box 356490, Seattle, WA 98195; 206-540-3193; fax: 206-540-3193.

Email: jpb26@u.washington.edu

DOI:10.1682/JRRD.2008.07.0085
} 
with many patients facing secondary disabling pain conditions such as phantom limb pain, residual limb pain, or back pain [2-4]. Most of these amputations are either transtibial or transfemoral, with knee-disarticulation amputations being relatively uncommon and representing less than 2 percent of all amputations [5]. The first kneedisarticulation amputation was documented in the United States in 1825 [1,6-7] and, before the advent of modern anesthesia, was a favored surgical procedure because of its simplicity and speed, decreased risk of infection, and decreased rate of bleeding because the procedure did not violate any muscle bellies or the medullary cavity of any bones [1,6,8-10]. However, by 1940, knee-disarticulation amputations had fallen out of favor because of concerns regarding a bulky distal limb, which many people with amputation did not find aesthetically pleasing; poor prosthetic fit; and improved surgical techniques for transtibial and transfemoral amputations [5,9,11].

In 1940, Rogers reopened the discussion regarding the role of knee-disarticulation amputation by extolling its virtues in terms of end weight bearing and the uninterrupted femoral epiphysis [9]. Since that time, the procedure has been controversial, with both enthusiastic supporters and ardent skeptics. However, in the last three decades, significant advances in both surgical technique and prosthetic technologies have occurred that make knee-disarticulation amputations potentially more viable and better tolerated than in the past [1,12-20]. One major advancement was achieved by Wagner, who in 1979 described his technique for dispersing normal and shear forces by constructing a distal soft tissue flap using the gastrocnemius and sagittal flaps [2]. This advancement offers the theoretical advantage of enabling more comfortable end weight bearing within the prosthetic socket, thus decreasing residual limb pain during ambulation. Additionally, numerous strategies have been developed to decrease distal bulk, including trimming of the medial and lateral condyles and excision of the patella [5,2122]. One commonly described disadvantage of the kneedisarticulation amputation is that the prosthetic knee center must be placed distal to the intact femur, thus making the prosthetic limb thigh segment longer than the intact limb thigh segment. This issue was addressed in 1976 by Lyquist, a prosthetist at the Orthopedic Hospital of Copenhagen, Denmark, who developed a four-bar linkage polycentric knee that compensates for the disparity in limb segment lengths [18,23-24] and had the advantage of creating an intrinsically more stable knee during the stance phase of gait because of the posteriorly positioned center of rotation.

Utilizing the four-bar linkage knee, patients with knee-disarticulation amputations have better physiological costs of walking than do patients with transfemoral amputation [25-27]. This improvement was most clearly demonstrated in 1992 by Pinzur et al., who demonstrated that persons with knee-disarticulation amputation have improved self-selected and maximal walking speeds than do persons with transfemoral amputation and that the relative energy cost of ambulation is closer to that of persons with transtibial rather than transfemoral amputation [28].

Despite recent improvements in surgical technique and advances in prosthetic technology, knee-disarticulation amputations are currently infrequently utilized and are performed predominantly on elderly patients, pediatric patients, spinal cord injury patients, and nonambulatory patients. Knee-disarticulation amputation is traditionally used in these patient populations with the goal of improving seating and transfer possibilities, as well as eliminating the risk of knee contracture $[5,22,29]$. Recently, kneedisarticulation amputations have fallen out of favor in the trauma setting partly because of the results of a multicenter study by the Lower Extremity Assessment Project (LEAP) [30]. This prospective observational study found worse outcomes in trauma patients with knee disarticulation amputation than in patients with transtibial or transfemoral amputations. Specifically, they found that the patients with knee-disarticulation amputation did worse on their primary outcome measure, the Sickness Impact Profile (SIP), a 136-item behaviorally based health status questionnaire, although this finding was not statistically significant. Secondary outcome measures demonstrated that the knee-disarticulation amputation group had significantly slower self-selected walking speeds and significantly more difficulty walking on uneven ground and outdoors in bad weather. This study also found a nonsignificant report of less pain in the knee-disarticulation amputation group versus the other amputation levels. To our knowledge, no subsequent study to date has further evaluated whether patients with knee-disarticulation amputations indeed have less pain than those with transfemoral or transtibial amputations.

Pain is well known to be a significant cause of morbidity and secondary disability due to impaired function and a significant determinant of patient satisfaction in both the general population and in individuals with 
amputation [3-4,31]. Therefore, in the assessment of outcomes of various levels of amputations, assessing both pain and pain-related interference with physical function is particularly important because of the high levels of reported phantom limb pain, residual limb pain, and back pain in the amputation population. Phantom limb pain, defined as painful sensations perceived in the missing portion of the amputated limb, has been estimated to occur chronically in up to 85 percent of amputation patients [32-34]. Residual limb pain is universal in the postoperative period and has an estimated chronic prevalence of between 20 and 56 percent [34-36]. Finally, back pain is thought to have an increased incidence in individuals with amputation because of altered gait patterns related to prosthesis use, with a prevalence of more than 50 percent reported in a sample of persons with lower-limb amputation [37-38].

To our knowledge, pain and its interference with physical function have rarely been studied in individuals with amputation [39] and never been compared among knee-disarticulation, transtibial, and transfemoral amputation levels. Our current study systematically compared persons with knee-disarticulation amputation with persons with transtibial and transfemoral amputations in terms of pain, pain-related interference with physical function, and prosthesis use. Knee-disarticulation surgery is performed relatively frequently at our institution and clinically we have observed favorable results that contrast with the results noted in the LEAP trial. In light of these anecdotal results, we specifically hypothesized that in our sample, which included trauma patients, the kneedisarticulation amputation patients would do no worse, and perhaps would do better, than transfemoral and transtibial amputation patients in terms of pain and painrelated interference with physical function.

\section{METHODS}

\section{Participants}

Study participants were drawn from a survey study on the nature and scope of pain in persons with limb loss [39]. Participants were recruited from several sources, including a pool of individuals who had undergone a lower-limb amputation at two Seattle-area, hospitalsHarborview Medical Center, a level I trauma center, and the Department of Veterans Affairs Puget Sound Health Care System—and one Spokane-area hospital—St. Luke’s
Hospital. Other recruitment sources included flyers posted in local prosthetic and orthotic clinics and an advertisement in the inMotion magazine, a publication by the Amputee Coalition of America. Inclusion criteria were (1) lower-limb amputation at least 6 months before the study, (2) age between 18 and 70 years, and (3) ability to read and write English. The University of Washington Human Subjects Committee approved the study protocol.

\section{Procedure}

From the total pool of potential participants in the hospital databases, patient names were selected via a random number generator. Approximately 70 surveys were mailed each month for 13 months. Potential subjects also called or emailed the study personnel in response to the flyers or the magazine advertisement. Each potential subject received by mail a packet containing a cover letter, the pain survey, and a stamped envelope for returning the completed survey. The cover letter instructed respondents to complete the survey even if they did not have pain. To facilitate recruitment, follow-up calls and postcard mailings were made to those who had not returned the survey. A research assistant contacted participants by telephone to obtain or clarify any answers that were incomplete or incomprehensible on the completed survey. Questionnaires were mailed to a total of 1,307 individuals. Of these, 220 were returned as undeliverable, 102 were returned as addressee deceased, and 143 were returned as inappropriate (e.g., $<6$ months postamputation, $<18$ years of age). Twenty-three potential participants declined to participate. A total of 478 usable surveys were returned, yielding a response rate of 57 percent.

\section{Matching Procedure}

Fourteen participants reported a single kneedisarticulation amputation and no other amputations. For the current analysis, each of these 14 individuals was matched on a case-by-case basis with 14 individuals reporting a single transfemoral amputation and no other amputations and 14 reporting a single transtibial amputation and no other amputations. Participants were matched based on time since amputation, reason for amputation, age, sex, report of pain before amputation, and diabetes diagnosis (yes/no). This matching procedure was intended to minimize differences due to clinical factors that might also affect outcomes (e.g., vascular vs traumatic etiology of amputation, history of pain problems, greater time lapsed since amputation). Thirteen patients, 
or 31 percent of our sample size, reported having diabetes, and this did not differ based on the amputation site. The matching procedure was successful in that no differences were found between groups $(p>0.80)$ for each matching variable.

\section{Measures}

\section{Demographics}

Participants provided information regarding age, race/ ethnicity, educational level, and employment status. They also completed questions regarding their amputation, including the medical reason for amputation, presence/ absence of ulcers at the amputation site, number of prostheses used, hours of daily prosthesis use, pain during prosthesis use, and whether or not they had undergone revision surgery since the original amputation.

\section{Pain Intensity/Interference}

Intensity of current phantom limb pain, defined as painful phantom sensations; back pain; and residual limb pain were assessed with a standard numeric rating scale ranging from 0 (no pain) to 10 (pain as bad as could be). Pain interference with daily activity over the past 3 months was also assessed with a numeric rating scale ranging from 0 (no interference) to 10 (unable to carry on any activities). Survey questions are included in Tables 1 and $\mathbf{2}$.

\section{Statistical Approach}

Continuous outcome measures were analyzed by a one-way analysis of variance (ANOVA) procedure with amputation site (transfemoral amputation, kneedisarticulation amputation, transtibial amputation) serving as the between-subjects variable. Given the relatively small sample size, we also relied on Cohen's $d$, a measure of effect size, to describe group differences. Cohen's $d$ is defined as the difference between two means divided by the pooled standard deviation (SD) for those means and is a useful way to conceptualize the magnitude of difference between groups when traditional parametric testing is not appropriate (e.g., because of small sample size). Although interpretations of Cohen's $d$ vary, most researchers consider 0.20 to 0.40 a small effect, 0.40 to 0.80 a medium effect, and $>0.80$ a large effect [40]. Analyses were conducted with the use of SPSS software (version 14.0, SPSS Inc; Chicago, Illinois).

\section{RESULTS}

\section{Demographics}

The majority of the 42 participants were male (83\%) and ranged in age from 36 to 85 years old (median age = $55.1, \mathrm{SD}=11.0)$. Nearly all participants $(97 \%)$ reported completing at least a high school education, and the majority (62\%) had some college experience or were college graduates. Full- or part-time employment was reported by 36 percent of participants and unemployment due to pain or disability by 45 percent. Self-report of ulcers at the amputation site did not differ among the groups, with three members of each group reporting the presence of ulcers ( $\chi^{2}=0.09$, not significant) Participants were mostly Caucasian (95\%); two participants were African American (5\%). Participants reported between one and three primary causes of the limb loss, including trauma (74\%), vascular disease (24\%), gangrene $(17 \%)$, and infection (12\%). At the time of the survey, participants were on average 12.4 years from their amputation surgeries ( $\mathrm{SD}=14.9$, range $=7$ months to 56.3 years $)$.

\section{Prosthesis Use}

Of the 42 participants enrolled in the study, 37 owned and wore prostheses. Of the 5 subjects who did not wear prostheses, 2 were in the transfemoral amputation group and 3 were in the knee-disarticulation amputation group. All 14 subjects in the transtibial amputation group wore prostheses. ANOVA testing demonstrated that the transtibial amputation group wore their prostheses significantly more than the knee-disarticulation amputation group $(p<0.05)$. No statistically significant difference was found between the knee-disarticulation and transfemoral amputation groups in terms of hours per day of prosthesis use (Tables 1 and 2).

Estimating effect size using Cohen's $d$, we found that the transtibial amputation group wore their prostheses more hours per day than the knee-disarticulation amputation group ( $d=-1.00$, large effect size; Table 1) and that the transfemoral group wore their prostheses more than the knee-disarticulation group ( $d=-0.21$, small effect size; Table 1).

\section{Phantom Limb Pain}

Phantom limb pain is defined as painful sensations that feel as though they are coming from the portion of the limb that was amputated and that differ from nonpainful phantom limb sensations. Of the 42 total participants 
Table 1.

Descriptive statistics and effect size estimates of transfemoral amputation (TFA), transtibial amputation (TTA), and knee-disarticulation amputation (TKA).

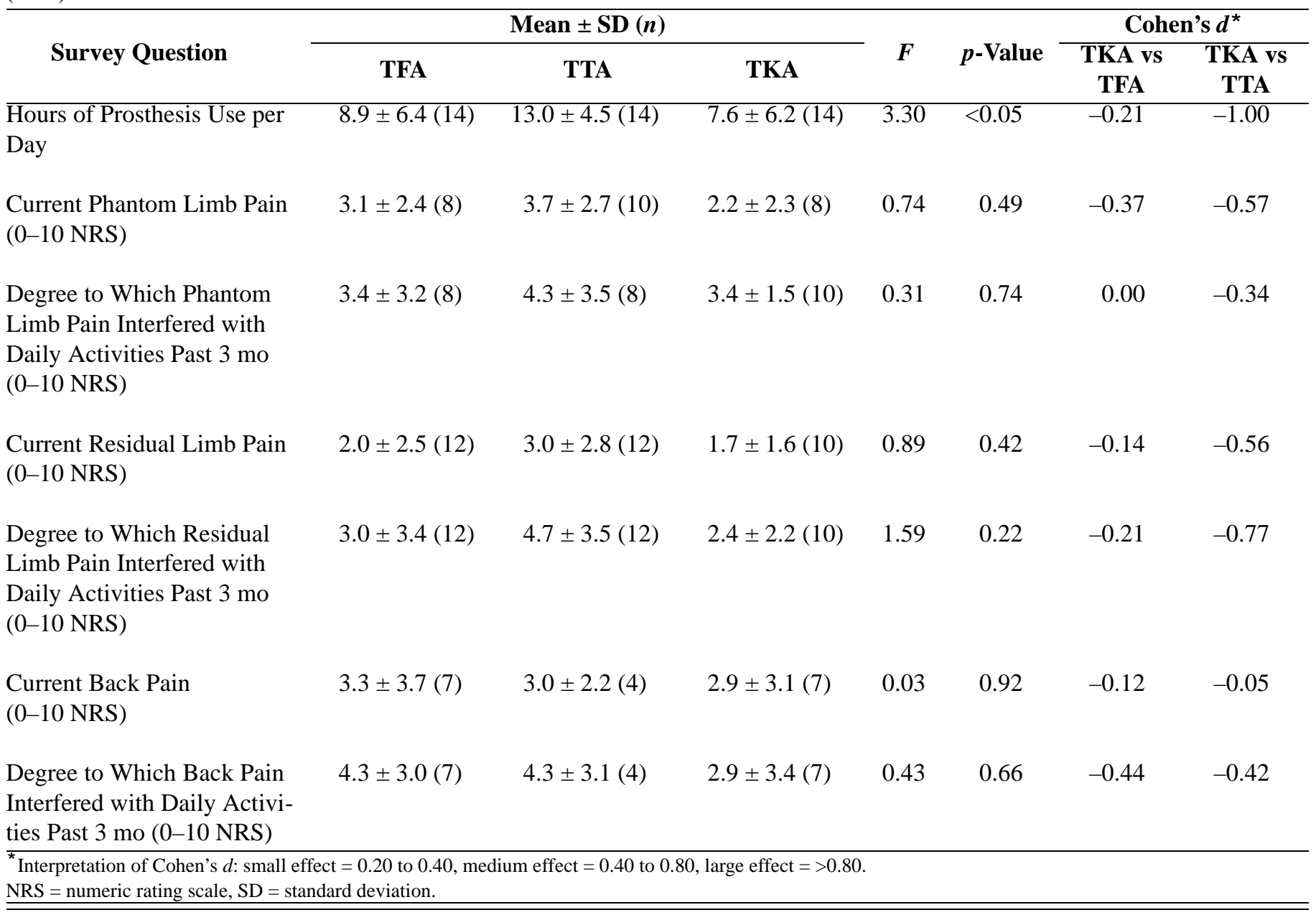

enrolled in the study, 6 in the transfemoral amputation group, 6 in the knee-disarticulation amputation group, and 4 in the transtibial amputation group denied phantom limb pain and therefore did not answer further study questions regarding phantom limb pain and phantom limb pain-related interference. We therefore performed ANOVA both imputing these participants as having answered 0/10 and excluding them from further analysis. Neither method demonstrated statistically significant differences between the three groups in terms of current phantom limb pain and degree to which phantom limb pain interfered with daily activities in the past 3 months as measured on the 0-10 numeric rating scale (Tables 1 and 2).

Estimating effect size using Cohen's $d$, we found that the knee-disarticulation amputation group reported less current phantom limb pain on the $0-10$ numeric rating scale than the transfemoral amputation group $(d=-0.37$, small effect size) and the transtibial amputation group ( $d=$ -0.57 , medium effect size; Table 1). In terms of degree of phantom limb pain interference with daily activities in the past 3 months, no difference was found between the knee-disarticulation amputation and transfemoral amputation groups $(d=0)$; however, both the knee-disarticulation and transfemoral amputation groups reported less interference with daily activities in the past 3 months than the transtibial amputation group $(d=-0.34$, small effect size; Table 1).

\section{Residual Limb Pain}

Of the 42 patients enrolled in the study, 34 reported residual limb pain. There were 2 patients in the transfemoral amputation group, 2 in the transtibial amputation 
JRRD, Volume 46, Number 7, 2009

Table 2.

Pearson chi-square analysis of categorical outcome variables in transfemoral amputation (TFA), transtibial amputation (TTA), and kneedisarticulation amputation (TKA).

\begin{tabular}{|c|c|c|c|c|c|}
\hline \multirow{2}{*}{ Survey Question } & \multicolumn{3}{|c|}{ No. Affirmative ( $n=14$ /group) } & \multirow{2}{*}{$\chi^{2}$} & \multirow[b]{2}{*}{$p$-Value } \\
\hline & TFA & TTA & TKA & & \\
\hline Do You Wear a Prosthesis? & 12 & 14 & 11 & 3.18 & 0.20 \\
\hline $\begin{array}{l}\text { Do You Have Painful } \\
\text { Phantom Limb Sensations? }\end{array}$ & 8 & 10 & 8 & 0.81 & 0.67 \\
\hline $\begin{array}{l}\text { Do You Have Residual } \\
\text { Limb Pain? }\end{array}$ & 12 & 12 & 10 & 1.23 & 0.54 \\
\hline $\begin{array}{l}\text { Did You Have Back Pain } \\
\text { Before Your Amputation? }\end{array}$ & 1 & 1 & 7 & 3.77 & 0.44 \\
\hline $\begin{array}{l}\text { Since Your Amputation, } \\
\text { Have You Had Bothersome } \\
\text { Back Pain? }\end{array}$ & 7 & 4 & 7 & 2.30 & 0.32 \\
\hline
\end{tabular}

group, and 4 in the knee disarticulation amputation group who reported no residual limb pain. We therefore performed ANOVA both imputing these participants as having answered $0 / 10$ for residual limb pain interference and excluding them from further analysis. Neither method demonstrated statistically significant differences between the three groups in terms of residual limb pain and degree of residual limb pain interference with daily activity in the past 3 months on the $0-10$ numeric rating scale (Tables 1 and 2).

Estimating effect size using Cohen's $d$, we found that the knee-disarticulation amputation group had less current residual limb pain on the $0-10$ numeric scale than the transtibial amputation group $(d=-0.56$, medium effect size; Table 1) and that no effect size existed between the knee-disarticulation and transfemoral groups. In terms of degree of interference with daily activities because of residual limb pain in the past 3 months, the kneedisarticulation amputation group reported less interference than the transfemoral amputation group $(d=-0.21$, small effect size) and the transtibial amputation group ( $d=$ -0.77 , medium effect size; Table $\mathbf{1}$ ).

\section{Back Pain}

Of the 42 patients enrolled in the study, 24 patients reported troublesome back pain since their amputation: 8 in the transfemoral amputation group, 6 in the transtibial amputation group, and 10 in the knee-disarticulation amputation group. Of these, 1 in the transfemoral amputation group, 1 in the transtibial amputation group, and 3 in the knee-disarticulation amputation group reported back pain before their amputations. We therefore performed ANOVA both including these participants and excluding their data from further analysis. Neither method demonstrated statistically significant differences between the three groups in terms of back pain or degree of back pain-related interference with activity in the past 3 months on the $0-10$ numeric rating scale (Tables 1 and 2).

Estimating effect size using Cohen's $d$, we found no difference between the three study groups in terms of current back pain as measured on the $0-10$ numeric rating scale (Table 1). In terms of amount of interference with daily activities over the past 3 months because of back pain, the knee-disarticulation amputation group reported less interference than the transfemoral amputation group ( $d=-0.44$, medium effect size) and the transtibial amputation group $(d=-0.42$, medium effect size; Table 1).

\section{DISCUSSION AND CONCLUSIONS}

The findings from the current study demonstrate that individuals who underwent knee-disarticulation amputation have pain and pain-related interference outcomes similar to those of rigorously matched populations of individuals with either transtibial or transfemoral amputations. More specifically, results indicated that our sample of primarily trauma patients with knee-disarticulation amputations did no worse, and perhaps did better, than persons with other levels of amputation in terms of phantom limb pain and residual limb pain, as well as 
interference related to phantom limb or residual limb pain. A long-held, but to our knowledge rarely addressed, concern of knee-disarticulation amputations is that the disparate thigh segment length may result in biomechanical changes to gait patterns that can lead to increased back pain. However, after accounting for a prior history of back pain, we found no significant difference in back pain or back pain-related interference among the groups. In fact, when we look at effect size, individuals with knee-disarticulation amputations may experience less back pain-related interference than do individuals with other levels of amputation. Finally, the knee disarticulation-amputation group wore their prostheses significantly less than did the transtibial group. This difference in prosthesis use may be due to increased function of persons with transtibial amputation or may possibly be related to the bulbous residual limb of persons with kneedisarticulation amputation hindering not only prosthetic fit but also subsequent use.

Most recently, knee-disarticulation amputations have fallen out of favor in the trauma population in part because of the results from the LEAP study [30] that demonstrated worse outcomes with knee-disarticulation amputations than with transtibial and transfemoral amputations in a trauma population. The LEAP study reported that the knee-disarticulation amputation group had significantly slower self-selected walking speeds and more difficulty walking on uneven ground or outdoors in bad weather. Finally, the LEAP study noted that the individuals with knee-disarticulation amputation did worse on their primary outcome measure, the SIP, a 136-item behaviorally based health status questionnaire; however, this finding was not statistically significant.

Several potential explanations exist for the differences in outcomes between this current study and the LEAP trial [30]. The primary outcome in the LEAP trial was the SIP rather than pain and pain interference, as in our study. Also, the population included in our study was on average 12 years postamputation, whereas the LEAP trial reported outcomes up to only 24 months postamputation. This suggests the possibility of differences in outcomes in the early recovery phase as compared with longer term outcomes. Another potential explanation for the difference in findings is that in the LEAP study, 17 of the 18 patients in the knee-disarticulation amputation group had their amputation at the zone of injury level, which may have affected short-term healing and function. Because the current study was a self-reported out- comes study using a survey design, we do not have information regarding the quality of the soft tissue around the amputation site or any details regarding the clinical decision-making regarding level of amputation. However, all surgeries were performed at medical centers where the standard clinical practice is to consider knee disarticulation only when there is healthy tissue to provide distal soft tissue coverage. Our sample possibly included more persons with better-quality soft tissue envelopes and fewer zone-of-injury amputation sites. Further prospective clinical studies will be needed to determine whether, indeed, these and other clinical factors play a role in the outcomes following knee disarticulation.

Although our study and the LEAP study had a comparable number of participants with knee-disarticulation amputations (16 in the final analysis of the LEAP trial vs 14 in this study), the LEAP trial compared these patients with a much larger sample of subjects with transtibial amputation (81) and transfemoral amputation (27) rather than using a matched case design, as was done in our study. The LEAP trial utilized a logistic regression approach that controlled for known influential factors such as employment status, age, sex, ethnicity, health insurance, smoking, and history of prior injury. From a statistical perspective, this approach means that the groups were numerically unbalanced, which can influence significance testing. One strength of our study is our matched design, which naturally controlled for confounds and also allowed for equal sample sizes. Finally, although the LEAP trial reported significant overall (omnibus) differences based on parametric testing, it did not include follow-up testing to compare amputation groups or adjust the alpha (significance level) for multiple comparisons.

In conclusion, our study of a sample of primarily male, Caucasian, and middle-age-to-elderly adults with amputations found no significant differences between knee-disarticulation amputations and either transfemoral or transtibial amputations in terms of phantom limb pain, residual limb pain, back pain, or pain-related interference outcomes. Additionally, estimates of effect size suggest that persons with knee-disarticulation amputation may have less phantom limb pain, phantom limb pain-related interference, residual limb pain, residual limb painrelated interference, and back pain-related interference than do similar populations of person with transfemoral and transtibial amputations. These results call into question the limited use of knee-disarticulation amputations, 
and in light of the conflicting data available regarding outcomes between different levels of amputations, further research is warranted.

\section{LIMITATIONS AND FUTURE DIRECTIONS}

While the current study found that persons with knee-disarticulation amputation do not have significantly worse pain or pain-related interference outcomes than do persons with transtibial or transfemoral amputation, some limitations affect this study. This was a small study that was forced to rely on effect size measures, since finding significant outcomes was unlikely with our small sample size. Our study sample had heterogeneous etiologies for their amputations, which may have affected our results. This heterogeneity, however, was addressed with our rigorous matching procedure. Another limitation of our study is that our sample predominantly consisted of Caucasian males. Data from our hospital system suggests that, as in the current study, a majority of through-knee amputations are performed on men. However, this sample may have overrepresented Caucasians, because some existing literature suggests that approximately 25 percent of amputations for vascular disease are performed on African Americans [41]. Because our study was a matched design, this limitation is unlikely to have changed our findings, although further studies to confirm these findings in other populations are warranted.

This study raises questions about the current role of knee-disarticulation amputations, particularly as compared with other levels of amputation, such as transfemoral and transtibial. Because the results of this study demonstrated more favorable outcomes following through-knee amputation than did the LEAP trial (which demonstrated worse functional outcomes in their through-knee amputation group), further studies are needed to further understand these conflicting results. For example, a prospective study with clinical data on the surgical technique and indications for amputation and in which participants are followed for several years postoperatively in terms of both objective and self-reported outcomes would be ideal (because a randomized trial is obviously not possible). In addition, in light of the results of the current study, further research utilizing a larger sample size and validated outcome measures is necessary. In amputation research in general, outcome measures are needed to assess functional outcomes, pain, and pros- thetic fit in both the short- and long-term and to compare different levels of amputations.

\section{ACKNOWLEDGMENTS}

\section{Author Contributions:}

Study concept and design: J. Behr, J. Friedly.

Analysis and interpretation of data: J. Behr, J. Friedly, I. Molton. Drafting of manuscript: J. Behr, I. Molton, D. Morgenroth.

Study supervision: J. Friedly.

Critical revision of manuscript for important intellectual content:

I. Molton, D. Morgenroth.

Statistical analysis: I. Molton.

Acquisition of data: M. P. Jensen, D. G. Smith.

Obtained funding: M. P. Jensen.

Administrative, technical, or material support: M. P. Jensen.

Financial Disclosures: The authors have declared that no competing interests exist.

Funding/Support: This material was based on work supported by grant number P01 HD33988 from the National Institutes of Health, National Institute of Child Health and Human Development, National Institute of Neurological Disorders and Stroke, and National Center for Rehabilitation Research.

Additional Contributions: We gratefully acknowledge the contributions of Kevin Gertz, Amy Hoffman, Beth Gerrard, Bridget Bjork,

Catherine McClellan, Erica Tyler, Cindy Davis, and Kim McKearnan, University of Washington Department of Rehabilitation Medicine, in data collection and database management. Dr. Behr is now with Orthopaedic Associates of South Carolina.

Participant Follow-Up: The authors do not plan to inform participants of the publication of this study.

\section{REFERENCES}

1. Harness N, Pinzur MS. Health related quality of life in patients with dysvascular transtibial amputation. Clin Orthop Relat Res. 2001;(383):204-207. [PMID: 11210955] DOI:10.1097/00003086-200102000-00023

2. Wagner FW Jr. Management of the diabetic-neurotrophic foot. Part II. A classification and treatment program for diabetic, neuropathic, and dysvascular foot problems. In: Instructional Course Lectures, American Academy of Orthopaedic Surgeons. Vol. 28. St. Louis (MO): C. V. Mosby; 1979. p. 143-65.

3. Jensen MP, Smith DG, Ehde DM, Robinsin LR. Pain site and the effects of amputation pain: Further clarification of the meaning of mild, moderate, and severe pain. Pain. 2001;91(3):317-22. [PMID: 11275389]

DOI:10.1016/S0304-3959(00)00459-0

4. Turner JA, Franklin G, Heagerty PJ, Wu R, Egan K, FultonKehoe D, Gluck JV, Wickizer TM. The association between pain and disability. Pain. 2004;112(3):307-14. 


\section{[PMID: 15561386]}

\section{DOI:10.1016/j.pain.2004.09.010}

5. Smith DG. The knee disarticulation: It's better when it's better and it's not when it's not. inMotion. 2004;14(1):56-62.

6. Batch JW, Spittler AW, McFadden JG. Advantages of the knee disarticulation over amputations through the thigh. J Bone Joint Surg Am. 1954;36-A(5):921-30. [PMID: 13211689]

7. Pinzur MS. Knee disarticulation: Surgical procedures. In: Bowker JH, editor. Atlas of limb prosthetics: Surgical, prosthetic, and rehabilitation principles. St. Louis (MO): Mosby Year Book; 1992. p. 479-486.

8. Havlícek V, Janícek P, Berka I. [Disarticulation of the knee joint]. Acta Chir Orthop Traumatol Cech. 2003;70(2):95-99. Czech. [PMID: 12807042]

9. Rogers SP. Amputation at the knee joint. J Bone Joint Surg. 1940;22:973-79.

10. Warren E. An epitome of practical surgery for field and hospital. Richmond (VA): West \& Johnson; 1863. p. 142-46.

11. Mensch G. Physiotherapy following through-knee amputation. Prosthet Orthot Int. 1983;7(2):79-87. [PMID: 6622238]

12. Pinzur MS, Smith DG, Daluga DJ, Osterman H. Selection of patients for through-the-knee amputation. J Bone Joint Surg Am. 1988;70(5):746-50. [PMID: 3392068]

13. Steen Jensen J. Life expectancy and social consequences of through-knee amputations. Prosthet Orthot Int. 1983;7(2): 113-15. [PMID: 6622229]

14. Hughes J. Biomechanics of the through-knee prosthesis. Prosthet Orthot Int. 1983;7(2):96-99. [PMID: 6622241]

15. Stone PA, Flaherty SK, Aburahma AF, Hass SM, Jackson JM, Hayes JD, Hofeldt MJ, Hager CS, Elmore MS. Factors affecting perioperative mortality and wound-related complications following major lower extremity amputations. Ann Vasc Surg. 2006;20(2):209-16. [PMID: 16586027] DOI:10.1007/s10016-006-9009-z

16. Kock HJ, Friederichs J, Ouchmaev A, Hillmeier J, Von Gumppenberg S. Long-term results of through-knee amputation with dorsal musculocutaneous flap in patients with end-stage arterial occlusive disease. World J Surg. 2004; 28(8):801-806. [PMID: 15457362]

DOI:10.1007/s00268-004-7311-X

17. Nellis N, Van De Water JM. Through-the-knee amputation: An improved technique. Am Surg. 2002;68(5):466-69. [PMID: 12013292]

18. Baumgartner RF. Knee disarticulation versus above-knee amputation. Prosthet Orthot Int. 1979;3(1):15-19.

[PMID: 471700]

19. Jansen K, Steen Jensen J. Operative technique in knee disarticulation. Prosthet Orthot Int. 1983;7(2):72-74. [PMID: 6622236]
20. Goralink B. Some clinical experience with the O.H.C. knee disarticulation prosthesis. J Prosthet Orthot. 1976;30(2):29.

21. Bowker JH, San Giovanni TP, Pinzur MS. North American experience with knee disarticulation with use of a posterior myofasciocutaneous flap. Healing rate and functional results in seventy-seven patients. J Bone Joint Surg Am. 2000;82-A(11):1571-74. [PMID: 11097446]

22. Pinzur MS, Bowker JH. Knee disarticulation. Clin Orthop Relat Res. 1999;(361):23-28. [PMID: 10212592]

DOI:10.1097/00003086-199904000-00004

23. Lyquist E. The OHC knee-disarticulation prosthesis. Orthot Prosthet. 1976;30:27-28.

24. Green MP. Four bar linkage knee analysis. Prosthet Orthot Int. 1983;34:15-24.

25. Pinzur MS. Gait analysis in peripheral vascular insufficiency through-knee amputation. J Rehabil Res Dev. 1993; 30(4):388-92. [PMID: 8158554

26. Waters RL, Perry J, Antonelli D, Hislop H. Energy cost of walking of amputees: The influence of level of amputation. J Bone Joint Surg Am. 1976;58(1):42-46. [PMID: 1249111]

27. Fisher SV, Gullickson G Jr. Energy cost of ambulation in health and disability: A literature review. Arch Phys Med Rehabil. 1978;59(3):124-33. [PMID: 148252]

28. Pinzur MS, Gold J, Schwartz D, Gross N. Energy demands for walking in dysvascular amputees as related to the level of amputation. Orthopedics. 1992;15(9):1033-37.

[PMID: 1437862]

29. Siev-Ner I, Heim M, Wershavski M, Adunsky A, Azariat M. Why knee disarticulation (through-knee-amputation) is appropriate for non ambulatory patients. Disabil Rehabil. 2000;22(18):862-64. [PMID: 11197523]

DOI:10.1080/09638280050207910

30. MacKenzie EJ, Bosse MJ, Castillo RC, Smith DG, Webb LX, Kellam JF, Burgess AR, Swiontkowski MF, Sanders RW, Jones AL, McAndrew MP, Patterson BM, Travison TG, McCarthy ML. Functional outcomes following traumarelated lower-extremity amputation. J Bone Joint Surg Am. 2004;86-A(8):1636-45. [PMID: 15292410] Erratum in: J Bone Joint Surg Am. 2004 Nov;86-A(11):2503.

31. O’Toole RV, Castillo RC, Pollak AN, MacKenzie EJ, Bosse MJ, LEAP Study Group. Determinants of patient satisfaction after severe lower-extremity injuries. J Bone Joint Surg Am. 2008;90(6):1206-11. [PMID: 18519312] DOI:10.2106/JBJS.G.00492

32. Sherman RA. Stump and phantom limb pain. Neurol Clin. 1989;7(2):249-64. [PMID: 2657377]

33. Sherman RA, Devor M, Jones DE, Katz J, Heermann-Do K. Phantom pain. New York (NY): Plenum Press; 1997.

34. Jensen TS, Krebs B, Nielsen J, Rasmussen P. Immediate and long-term phantom limb pain in amputees: Incidence, clinical characteristics and relationship to pre-amputation 
JRRD, Volume 46, Number 7, 2009

limb pain. Pain. 1985;21(3):267-78. [PMID: 3991231]

DOI:10.1016/0304-3959(85)90090-9

35. Davis RW. Phantom sensation, phantom pain, and stump pain. Arch Phys Med Rehabil. 1993;74(1):79-91. [PMID: 8380543$]$

36. Melzack R. Phantom limb pain. Patol Fiziol Eksp Ter. 1992(4):52-54. [PMID: 1303505]

37. Smith DG, Ehde DM, Legro MW, Reiber GE, Del Aguila M, Boone DA. Phantom limb, residual limb, and back pain after lower extremity amputations. Clin Orthop Relat Res. 1999(361):29-38. [PMID: 10212593] DOI:10.1097/00003086-199904000-00005

38. Ehde DM, Smith DG, Czerniecki JM, Campbell KM, Malchow DM, Robinson LR. Back pain as a secondary disability in persons with lower limb amputations. Arch Phys Med Rehabil. 2001;82(6):731-34. [PMID: 11387575] DOI:10.1053/apmr.2001.21962
39. Ehde DM, Czerniecki JM, Smith DG, Campbell KM, Edwards WT, Jensen MP, Robinson LR. Chronic phantom sensations, phantom pain, residual limb pain, and other regional pain after lower limb amputation. Arch Phys Med Rehabil. 2000;81(8):1039-44. [PMID: 10943752] DOI:10.1053/apmr.2000.7583

40. Cohen J. A power primer. Psychol Bull. 1992;112(1):155-59. [PMID: 19565683] DOI:10.1037/0033-2909.112.1.155

41. Dillingham TR, Pezzin LE, Shore AD. Reamputation, mortality, and health care costs among persons with dysvascular lower-limb amputations. Arch Phys Med Rehabil. 2005;86(3):480-86. [PMID: 15759232]

DOI:10.1016/j.apmr.2004.06.072

Submitted for publication September 15, 2008. Accepted in revised form April 2, 2009. 